\title{
A model for cognitively-based compassion training: theoretical underpinnings and proposed mechanisms
}

\author{
Marcia Ash ${ }^{1} \cdot$ Timothy Harrison $^{2} \cdot$ Melissa Pinto $^{3} \cdot$ Ralph DiClemente $^{4}$. \\ Lobsang Tenzin Negi ${ }^{2}$
}

Published online: 13 December 2019

(c) The Author(s) 2019

\begin{abstract}
Across cultures and belief systems, compassion is widely considered to be beneficial for the development of personal and social wellbeing. Research indicates that compassion-training programs have broad health benefits, but how and why compassiontraining programs are effective is still relatively unknown. This paper describes the theoretical underpinnings of a specific compassion-training program, $\mathrm{CBCT}^{\circledR}(\mathrm{Cog}$ nitively-Based Compassion Training), and proposes an integrative model that draws on existing health behavior constructs to identify CBCT's core components and hypothesizes their directionality and interaction. The model includes two primary categories of skill development: (1) intrapersonal skills leading to greater resiliency, and (2) interpersonal skills leading to greater compassion. It is hypothesized that these two pathways are mutually reinforcing and both contribute to greater wellbeing. This model provides a foundation for theory-driven research on the underlying mechanisms in CBCT training. An understanding of CBCT's mechanisms is a critical step towards optimizing and personalizing the intervention to meet the needs of specific populations.
\end{abstract}

Keywords Compassion - Wellbeing · Resilience $\cdot$ Contemplative practice . Mechanisms of behavior change

\section{Introduction}

The purpose of this paper is to provide a conceptual model that explains how the components of Cognitively-Based Compassion Training $\left(\mathrm{CBCT}^{\circledR}\right)$ lead to greater resilience, compassion, and wellbeing. There is a compelling body of evidence to support the role of compassion in improving health and wellbeing (Hofmann et al. 2011; Kirby 2017; Seppala et al. 2017). Prior studies suggest

Marcia Ash

mjash@emory.edu

Extended author information available on the last page of the article 
that compassion appears to be a trainable skill; yet methods for cultivating compassion vary across compassion-based protocols. Some compassion-training programs use a process of cognitive reframing to cultivate a wish to see others free from suffering (Jazaieri et al. 2012; Ozawa-de Silva and Dodson-Lavelle 2011). Other related practices include loving-kindness meditations (LKM) which involve a repeated process of wishing others to be happy (Shonin et al. 2014). Current compassion-training programs, including CBCT (Pace et al. 2009), Compassion Cultivation Training (Jazaieri et al. 2012), Mindful Self-Compassion (Neff and Germer 2013), Compassion-Focused Therapy (Gilbert 2014), and MindfulnessBased Compassionate Living (Schuling et al. 2018), have been conceptualized under broad frameworks (e.g., compassion meditation (CM)) with modest emphasis on describing the specific practices and pedagogical models.

A recent meta-analysis of existing compassion-based interventions emphasized the need for thorough articulations of the theoretical underpinnings of current compassion interventions (Kirby 2017). There are relatively few theoretical accounts that address the relationship among key concepts and practices that are critical to the science of compassion training (for examples of existing theoretical accounts, see Mascaro et al. 2015). Just as different types of physical exercise result in measurably distinct changes to the body, one would expect that different practices of cultivating compassion may lead to identifiably distinct outcomes. While CBCT has been studied across diverse populations and settings (Desbordes et al. 2012; LoParo et al. 2018; Mascaro et al. 2013; Pace et al. 2009; Reddy et al. 2012), no synthesis is published which provides a comprehensive overview of the CBCT protocol and its theoretical underpinnings. This paper seeks to fill this gap by providing an overview of the theory and practices guiding CBCT.

While CBCT has been previously shown to be an effective intervention to reduce depression and other negative health symptoms (Desbordes et al. 2012; Mascaro et al. 2016), there is a lack of empirical research addressing the mechanisms of change in a CBCT intervention. Here, we adopt the National Institute of Health (NIH) Science of Behavior Change definition which refers to mechanisms of behavior change as "malleable targets that play a role in initiating or maintaining behavior change" (Nielsen et al. 2018). Mechanisms of behavior change could take place at different levels of analysis including the psychological, social, cultural or structural. In the case of the CBCT integrative model, 'mechanisms of change' refer to the relationships among psychosocial skills developed through participation in CBCT that are expected to lead to the outcomes of interest: resilience, compassion, and wellbeing. The National Institute of Health (NIH) Science of Behavior Change Program emphasizes the importance of utilizing mechanism-focused methods to understand how and why interventions work to effectively optimize and personalize behavioral interventions for specific populations (Nielsen et al. 2018). In keeping with that approach, this paper has two aims: (1) to provide a comprehensive overview of the theoretical underpinnings and practices of CBCT and (2) to propose a conceptual model that identifies the psychosocial constructs that influence change mechanisms in CBCT training. 


\section{Defining compassion}

Across existing compassion-training programs, compassion includes at least two key components: recognition of suffering and a motivation to help (Goetz et al. 2010; Lazarus 1991; Strauss et al. 2016). In CBCT, compassion is understood as a motivational state predicated on two necessary conditions: affection for others and an awareness of their distress. CBCT defines compassion as the warmhearted wish to see others free from suffering (Negi 2005; Ozawa-de Silva and Dodson-Lavelle 2011). Compassion involves an affective component reliant on feelings of affection for an individual or group and a cognitive component that includes the awareness of others' difficulties. This understanding of compassion as a multi-dimensional construct including both affective and cognitive qualities is consistent with research in affective neuroscience (Ashar et al. 2016; Dahl et al. 2016) as well as conceptions of compassion detailed in the writings of the Dalai Lama (2005), the leading spiritual figure in the Tibetan Buddhist tradition.

In the CBCT framework, affection is considered the most critical component for compassion to arise. While a feeling of affection for another is a precondition to compassionate behavior, compassion does not necessitate a behavioral change; the motivation to alleviate others' distress will frequently occur without knowledge or means of how to alleviate such distress. As such, CBCT does not provide prescriptive instruction on how to act compassionately in particular circumstances. Instead, CBCT trains participants in psychosocial skills that are expected to strengthen compassionate motivations which may prompt compassionate behavior, but the resultant actions are dependent on additional factors such as personal constraints (e.g. what is or is not in a person's control) and context.

CBCT distinguishes between two forms of compassion: biologically based compassion and extended compassion. This distinction is drawn according to the recipient of one's compassion. Biologically based compassion is rooted in a natural human tendency to feel affection towards one's kin. Attachment theory supports the view that from infancy people seek to maintain loving, supportive relationships (Bowlby 1982, 1988). Biologically based compassion serves as the foundation for extended compassion; without training, though, biologically based compassion is limited to those belonging to one's immediate inner circle (e.g. family and friends). Research with infants and young children suggests that from a young age, helping behavior is often limited to those perceived as familiar or similar to oneself (Hamlin et al. 2013; Wynn et al. 2017). CBCT provides a model for cultivating compassion that extends beyond one's immediate circle and includes strangers and even adversaries. CBCT endeavors to train participants to relate to others with increased affection by (1) seeing all others as similar to oneself in their desire for wellbeing and (2) developing increased gratitude for others. This training process occurs through the repeated practice of deliberate mental exercise often referred to as 'meditation' or 'contemplative practice.' The specifics of the meditation practices included in CBCT will be discussed later within the $C B C T$ Pedagogy section of this article. 


\section{Benefits of compassion training}

Benefits of compassion training include increased positive affect (Fredrickson et al. 2008), decreased self-reported worry (Jazaieri et al. 2013), and increased selfacceptance in response to anxiety (Jazaieri et al. 2017). Some research indicates the potential for compassion training to buffer psychological stress and, at a neurophysiological level, to alter the amygdala's response to witnessing others' suffering (Desbordes et al. 2012; Lutz et al. 2008a; Mascaro et al. 2016; Weng et al. 2013). Preliminary research suggests that compassion training can enhance pro-social behavior (Condon et al. 2013; Leiberg et al. 2011; Weng et al. 2013).

Research with CBCT has shown that participants exhibited a decreased response to stress including lower resting cortisol levels, increased recovery from cortisol surge due to social stress, and decreased inflammatory response (Pace et al. 2012; Pace et al. 2009, 2013). CBCT practice has also been associated with decreased depression (Desbordes et al. 2012; Mascaro et al. 2016) and increased empathic accuracy (Mascaro et al. 2013). CBCT has been tested among diverse groups of people-foster adolescents showed increases in levels of hopefulness (Reddy et al. 2012); breast cancer survivors reported decreased depression and increased psychological functioning (Dodds et al. 2015) as well as decreased stress related to fear of cancer recurrence (Gonzalez-Hernandez et al. 2018); and among a population of African American suicide attempters, CBCT participants showed increased levels of self-compassion which mediated depression outcomes (LoParo et al. 2018; Zhang et al. 2017). While current research highlights certain benefits associated with participation in a CBCT intervention, markedly less research has focused on identifying the possible mechanisms that give rise to these effects. The integrative model proposed in this paper presents a conceptual framework with the aim of providing a basis for further theory-driven research to investigate the processes for how and why CBCT promotes health and wellbeing.

\section{CBCT development}

CBCT was developed at Emory University in 2005 by Dr. Lobsang Tenzin Negi. CBCT was created as a secular compassion-based training program adapted from the Indo-Tibetan Buddhist traditions of lojong (mind training) and lamrim (the stages of the path for spiritual development) (for an overview see Jinpa et al. 2014; Kyabgon 2007). The definition of compassion adopted in CBCT is in alignment with IndoTibetan Buddhist conceptions of compassion (Dalai Lama 2005), though CBCT is presented entirely in non-religious terms. CBCT was intentionally designed to be accessible to persons of any or no faith tradition. Initially, the CBCT protocol consisted of eight distinct modules (Negi 2005). The CBCT protocol has undergone several revisions since its inception. Currently, the CBCT protocol includes a foundational practice followed by six modules (see Table 1).

Each CBCT module employs a meditation exercise (also referred to as "contemplative practice') as the primary training strategy. The bulk of scientific research on meditation has addressed mindfulness-based interventions such as 
Table 1 CBCT practice overview

\begin{tabular}{ll}
\hline CBCT modules & Practice topic \\
\hline Foundational practice: Resting in a moment of nurturance & The value of kindness \\
I. Attentional stability and clarity & The sensations of the breath \\
II. Insight into the nature of mental experience & The present-moment experience \\
III. Self-compassion & Personal ups and downs from a \\
& broader perspective \\
IV. Cultivating impartiality & Others' shared desire for wellbeing \\
V. Appreciation and affection & Interdependence \\
VI. Empathic concern and engaged compassion & Others' vulnerabilities
\end{tabular}

${ }^{a}$ Modules I and II are present-moment practices, while the foundational practice and Modules III-VI are primarily analytical practices

Mindfulness-Based Stress Reduction (MBSR) in which mindfulness is understood as a state of non-judgmental present-moment awareness (Kabat-Zinn 2013). These present-moment practices typically utilize introspective awareness to observe one's inner experience as it unfolds (i.e, watch one's thoughts and feelings) without reacting or analyzing. The CBCT protocol does include training in such present-moment practices; specifically, CBCT includes focused attention training (Module I) - typically practiced by focusing on the immediate sensations of breathing. CBCT also includes open monitoring practices (Module II) in which participants expand the focus of their attention to observe their unfolding sensations, thoughts, and feelings. The intended outcomes of these first two modules are attentional control and metaawareness, respectively, which are potentially beneficial in and of themselves, but in CBCT these skills are also taught as foundational tools to engage in the later analytical practices aimed at the cultivation of compassion.

CBCT-Cognitively Based Compassion Training - is aptly named because many of the reflective practices include cognitive reappraisal strategies that are categorized here as analytical meditation. Analytical meditation is a method for arriving at personal insights through critical thinking; it is a process of mental investigation including reflection and close examination of the $\mathrm{CBCT}$ practice topics in relation to one's own life experience. Table 1 outlines the practice topic for each CBCT module and indicates which modules emphasize present-moment practices and which emphasize analytical practices.

\section{CBCT pedagogy}

CBCT courses generally consist of 10 sessions taught over a 10 -week period, meeting $1.5 \mathrm{~h}$ per week. CBCT instructors complete a CBCT certification process that includes a 1-week retreat and workshop, an 8-week seminar, and a 10-week supervised teaching assistantship. CBCT sessions include a pedagogical overview by the certified instructor, guided meditations, and interactive exercises and discussion. Participants are provided with guided meditation recordings for each module and are 
expected to meditate $15-20 \mathrm{~min} /$ day. While this is the standard format for a general, adult CBCT course, the CBCT course structure and content have been adapted for other settings and populations.

\section{Process of skill acquisition}

The CBCT learning process utilizes two meditation strategies: (1) stabilizing meditation (sustained concentration) and (2) analytical meditation. Together, these strategies support the building of skills across three levels: content knowledge, personal insight, and embodied understanding. See Fig. 1.

\section{Content knowledge}

The first level of skill acquisition relies on learning from an outside source such as reading, hearing, or seeing. At this stage, content is understood on an intellectual level.

\section{Personal insight}

The second level of skill acquisition develops via a process of reflection, personalization, and critical thinking. In this process, one critically reflects on the content knowledge relative to one's own life experiences. The goal is to understand the content at a personal level, and the process is successful when it generates a deeply felt sense of understanding.
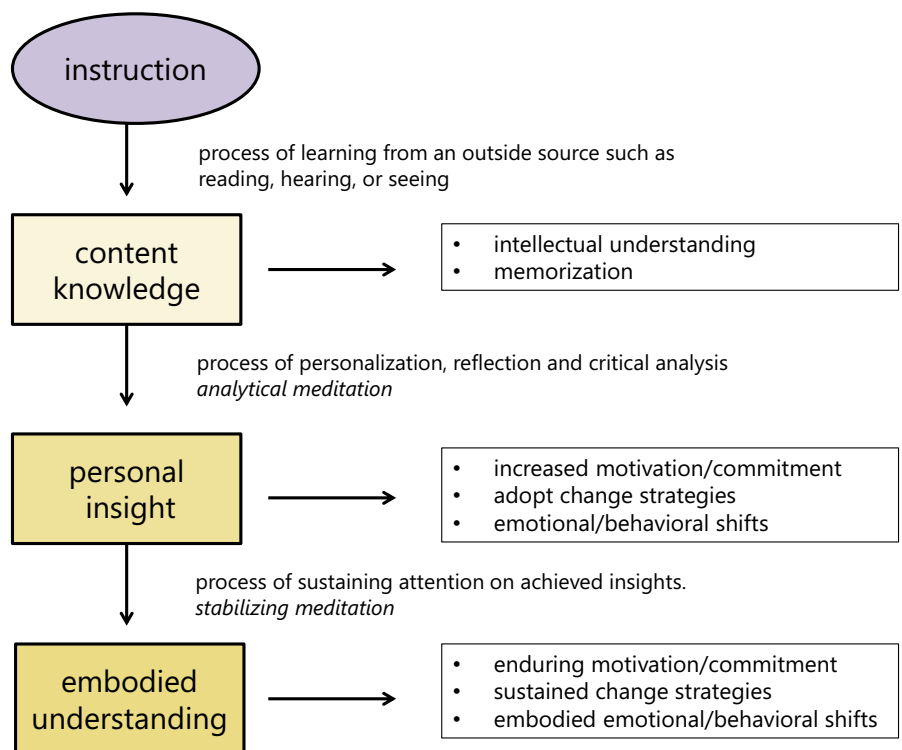

Fig. 1 CBCT process of skill acquisition 


\section{Embodied understanding}

Personal insight is considered insufficient for a lasting shift in mindset or long-term behavioral change. Once the personal insight is experienced, one purposefully sustains attention on the achieved personal insight. Through repeated practice, this insight becomes more embodied.

\section{CBCT practices}

The CBCT framework consists of a foundational practice and six modules that systemically build upon and integrate skills from prior modules. Each module aims to train specific skills, each of which are considered to be an active ingredient necessary for the cultivation of extended compassion. The practice instructions for each module are described below. A summary of the CBCT modules can be found in Table 1.

\section{Foundational practice: Resting in a Moment of Nurturance}

All CBCT practice sessions begin by resting in a moment of nurturance. Participants recall a time they felt cared for and safe. This might be a moment of receiving kindness from another person but it could also include peaceful experiences with an animal or in nature. Bringing the moment to mind in vivid detail, participants are instructed to notice, cultivate, and sustain associated feelings of safety and comfort.

\section{Module I: Attentional Stability and Clarity}

In Module I, participants direct their attention to a specific object, which in CBCT is typically the sensations of breathing. Participants are instructed to notice when their attention has wandered, disengage from the distraction without judgment, and return to the intended object of focus.

\section{Module II: Insights into the Nature of Mental Experience}

Module II practice utilizes attentional control skills cultivated in Module I and applies them to a less-specific object of focus (i.e., no longer the sensations of the breath). Participants are asked to observe sensations, thoughts, and feelings as they unfold and change over time without getting caught up in particular emotions or thoughts. The objective is to witness mental activity while resisting the urge to control, react, or judge the content. When such reactivity is observed, the instruction is to release the thought or feeling and return to observing present-moment experiences.

\section{Module III: Self-Compassion}

Module III is the first practice within the CBCT sequence in which participants are prompted to engage actively in cognitive reframing via analytical meditation. The goal of Module III is to strengthen a compassionate attitude towards oneself by 
re-examining one's imperfections, vulnerabilities, and adversities within a broader perspective than one is accustomed. First, participants are prompted to consider how their thoughts, emotions, and behaviors reflect an underlying desire for wellbeing, despite the presence of difficulties and distress in life. Through analytical exercises, participants consider which thoughts, emotions, and behaviors hinder their desired wellbeing and which support it, including whether they habitually respond to their own limitations with overly harsh self-judgment. They are then asked to reconsider personal difficulties in light of two realities: (1) all people experience adversities, limitations, and vulnerabilities and (2) outcomes are not fully in one's control because they depend on many causes and conditions. These reflections are designed to engender insight into underlying cognitive appraisals that often contribute to distress.

\section{Module IV: Cultivating Impartiality}

Module IV practice asks participants to examine their tendency to label others as belonging to one of three categories: dear one, stranger, or adversary. Through reflective exercises, including visualization of one person from each category, participants are prompted to consider the subjective and changing nature of these categories. Participants are asked to consider that like themselves individuals in all three groups share a desire for wellbeing. Recognition of the ways in which one is similar to others is intended to foster increased identification and, in turn, an increased sense of affection.

\section{Module V: Gratitude and Affection}

The reflective exercises in Module $\mathrm{V}$ prompt participants to consider the many ways they are dependent on others for their own wellbeing. For example, participants are prompted to consider all the people who have contributed to an object they routinely rely on, such as their mobile phone. How many people were involved in developing, manufacturing, packaging, and shipping a single phone? Participants are instructed to notice any feelings of gratitude that arise from considering how they benefit from the efforts of many others. Through visualizations of individuals, beginning with a dear one toward whom there is already a felt sense of gratitude, the increasing awareness of interdependence is called to mind to allow others to be included in the field of gratitude. When expanded feelings of gratitude emerge, the participant is instructed to sustain attention on the sense of gratitude; thus, allowing the insight to become more enduring over time.

\section{Module VI: Empathetic Concern and Engaged Compassion}

After cultivating increased affection for others in Module VI and V, the Module VI practice offers an opportunity to attune to the variety of ways others are suffering. Participants are instructed to call to mind someone they see as vulnerable and allow compassionate feelings to arise. Stabilizing techniques (developed in Module I and 
II) are then employed to sustain and strengthen the arising feelings of compassion. With practice, the compassionate feeling should deepen according to the CBCT process of skill acquisition (Fig. 1) such that it becomes a more abiding disposition for relating to others.

\section{CBCT integrative model}

The CBCT integrative model (Fig. 2) depicts the core skills developed in each CBCT module. The lines linking each construct in the model represent the proposed mechanistic pathway by indicating the direction and interaction of skills developed in each CBCT module and their contribution to the primary outcomes: resilience, compassion, and wellbeing. The CBCT integrative model is divided in two principal pathways: intrapersonal (Modules I-III) and interpersonal (Modules IV-VI). Intrapersonal skills, primarily focused on self-regulation skills and self-compassion, are intended to lead to greater psychological resilience. The latter half of the model addresses interpersonal skills with the goal of developing extended compassion for others. This model proposes that both pathways are mutually supportive and contribute to enhanced wellbeing. See Table 2 for definitions of each construct in the model. In building the CBCT integrative model, several assumptions were made: (1) CBCT modules are taught linearly, but the skills developed are mutually reinforcing and integrated both conceptually and through practice; (2) CBCT skills and outcomes can be strengthened with ongoing practice according to the proposed process of skill acquisition (Fig. 1); and (3) Competency in skills developed in Modules

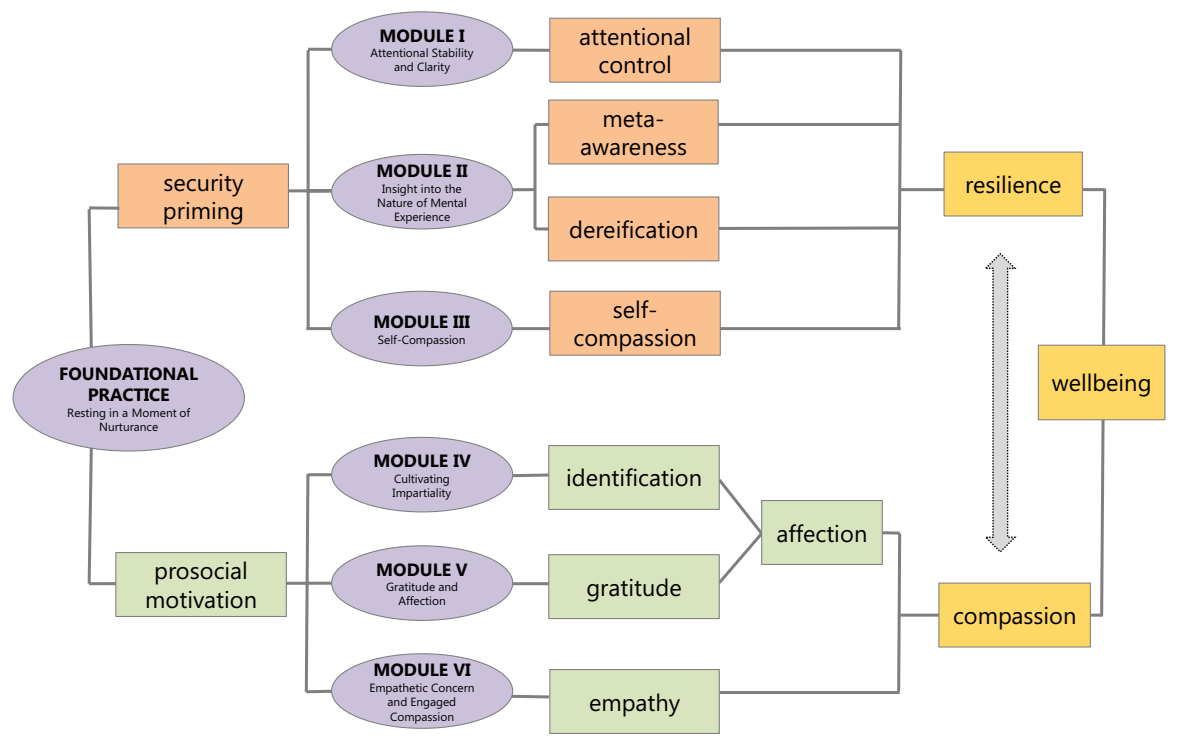

Fig. 2 CBCT integrative model 


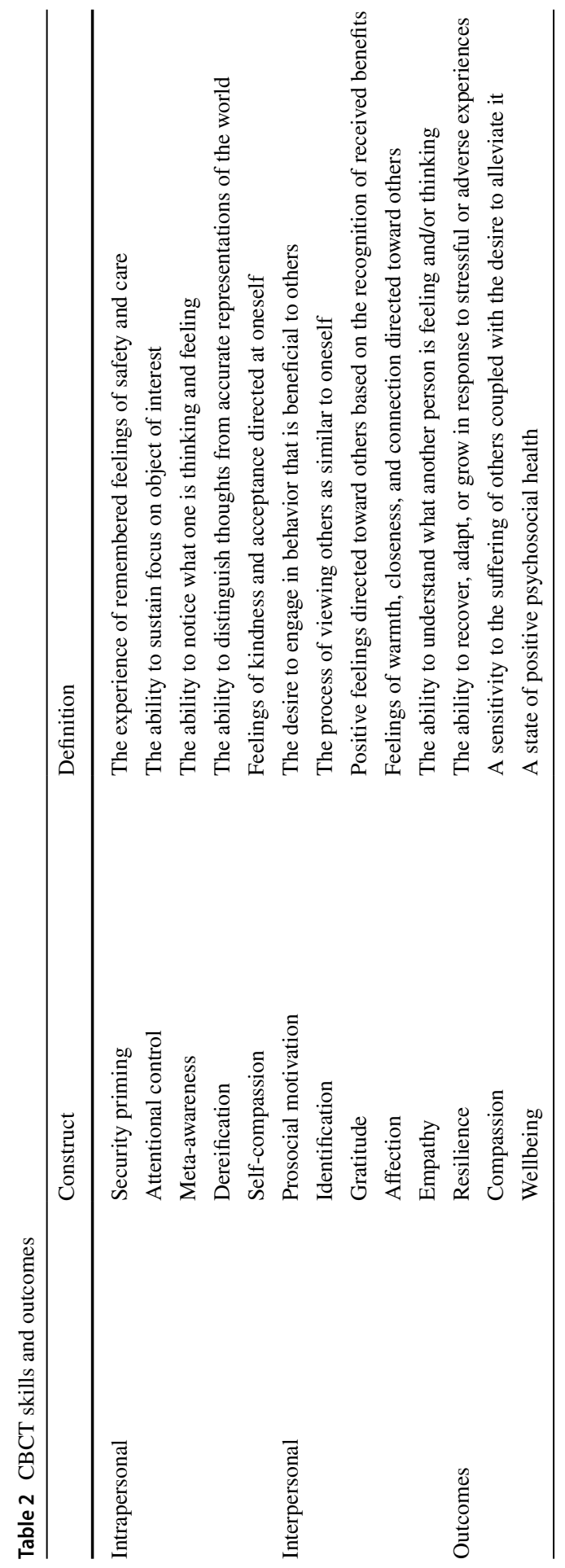

2. 
I and II is critical for engagement in analytical practices (Module III-VI) and each contributes to the principal outcomes: resilience and compassion.

An overview of each skill included in the CBCT integrative model can be found in the following section.

\section{Foundational practice skills: security priming and pro-social motivation}

The nurturing moment practice has two important functions as the foundational CBCT practice. Security priming - the ability to engender feelings of safety and comfort-is intended to ready the participants for learning by generating a sense of safety and openness. Within the domain of attachment theory (Bowlby 1982), secure attachment is associated with increased cognitive openness and flexibility (Collins and Read 1994; Mikulincer 1997). The foundational practice should allow participants to become more facile in voluntarily generating a sense of inner calm. In the CBCT integrative model, the ability to volitionally induce feelings of security is considered critical for the development of enhanced resilience.

Second, the foundational practice is intended to strengthen pro-social motivation by reminding participants of the value of compassion as a basis for developing and strengthening pro-social motivation. Prior literature supports that security priming promotes care-oriented feelings and behaviors (Mikulincer et al. $2005,2014)$. The pro-social motivation developed in the foundational practice is intended to allow participants to more energetically engage in the cultivation of compassion via the subsequent six modules. Thus, the foundational practice serves as the basis for the development of both intrapersonal and interpersonal skills as is depicted in the CBCT integrative model.

\section{Module I skill: attentional control}

The attentional control that is enhanced in Module I is considered a critical skill that is applicable to all other CBCT modules. Attentional control refers to the ability to sustain attention on an intended object of focus while noticing distractions and repeatedly returning to the intended object of focus. There is a robust array of research demonstrating that practicing mindfulness meditation (of which attention training is typically a central component) can improve attentional stability including improvements in alerting-response functioning and executive attention (Jha et al. 2007; Tsai and Chou 2016; van den Hurk et al. 2010).

\section{Module II skills: meta-awareness and dereification}

In Module II, participants gain insight into the impermanent nature of thoughts and emotions by observing their unfolding mental activity through a process of metaawareness. Meta-awareness has been defined as an ability to observe the current contents of one's conscious experience (Schooler 2002; Smallwood and Schooler 
2015). This definition is consistent with Indo-Tibetan Buddhist conceptions of metaawareness as most elaborately detailed in Abhidharma-Samuccaya (Asanga and Webb 2001). Noticing when one's mind has wandered involves processes of metaawareness. Several studies have shown that many people fail to recognize when their attention has wandered and only engage meta-awareness intermittently (Schooler 2002; Schooler et al. 2011; Winkielman and Schooler 2011). A second and related skill associated with Module II is dereification-sometimes referred to as decentering (Williams 2010). Dereification is the ability to experience thoughts as just thoughts and not necessarily accurate representations of the world; thus, Module II practice is often described as a process of non-appraisal (Lutz et al. 2015). Both meta-awareness and dereification are considered to be central dimensions of openmonitoring practices (Lutz et al. 2015; Lutz et al. 2008b). Module I and Module II together provide tools through present-moment practices that support the proposed CBCT process of skill acquisition (see Fig. 1).

\section{Module III skill: self-compassion}

Self-compassion is a burgeoning construct within the psychological literature (Neff 2015). Neff and colleagues who developed the Self-Compassion Scale define selfcompassion as relating to oneself with kindness, especially in times of difficulty or personal suffering (Neff 2003). While this definition is similar to CBCT's conception of self-compassion, CBCT frames self-compassion as both a skill to foster resilience and as an important component to support the cultivation of compassion for others in Modules IV-VI. For this reason, self-compassion is positioned as a moderating skill in the CBCT integrative model while compassion for others is considered a primary outcome of CBCT training. CBCT defines self-compassion as the ability to relate to personal difficulties in light of the reality that all people experience adversities, limitations, and vulnerabilities. Self-compassion is not only seen as a skill to promote personal happiness, but it is framed within a relational context. By cultivating confidence to be able to experience difficult situations without becoming overwhelmed, we expect the participant will become better able to respond to the suffering of others with greater compassion. Previous research has shown a strong negative association between self-compassion (measured by the Self-Compassion Scale) and several markers of psychopathology including depression, anxiety and stress (for overview, see MacBeth and Gumley 2012). A recent meta-analysis also highlighted significant associations between self-compassion and psychological wellbeing (Zessin et al. 2015). Research on the association between self-compassion and compassion for others, however, has had mixed findings which warrant further investigation (Lopez et al. 2018; Neff and Pommier 2013). Importantly, in the CBCT integrative model, the development of self-compassion and the development of compassion for others are understood to be mutually supportive. 


\section{Module IV skill: identification}

Module IV is the first module in the CBCT sequence that explicitly addresses relations with others. The primary skill developed in Module IV is a more inclusive sense of identification with others. Participants cultivate the insight that everyone, even difficult people, are "just like me" in their desire for wellbeing. Module IV practice is intended to soften feelings of extreme liking or disliking for certain individuals or groups. In CBCT's integrative model, the recognition of common humanity - that everyone shares the wish to thrive and to avoid suffering - is the basis for the cultivation of extended compassion.

Identification has been previously linked to increased likelihood of engaging in helping behavior. For example, experimental research by Levine and colleagues found that people are significantly more likely to stop and help someone wearing a T-shirt supporting their favorite sports team than an unmarked or rival group T-shirt (Levine et al. 2005). In the CBCT integrative model, identification is understood as a building block for relating to others with affection.

\section{Module V skill: gratitude}

The purpose of Module V is to deepen a sense of gratitude for others. Gratitude has been previously associated with a host of positive health benefits including better sleep quality, decreased depression, and overall wellbeing (Wood et al. 2009, 2010). Gratitude is also associated with increased social affiliation (Bartlett et al. 2012) and prosocial behavior (Bartlett and DeSteno 2006; Tsang and Martin 2019). While the benefits of gratitude are well documented, there still remains limited understanding regarding the process for how gratitude can be cultivated; nevertheless, modest evidence supports that journaling and reflection may provide a means for enhancing gratitude (Emmons and McCullough 2003; Frias et al. 2011; Sheldon and Lyubomirsky 2006).

In Module $\mathrm{V}$, participants engage in reflective strategies to extend feelings of gratitude to others. By considering the ways in which they rely on interdependent societal systems, Module V encourages participants to see that it does not make sense to limit appreciation to only small groups of people who provide the most obvious benefit. In the CBCT integrative model, it is assumed that if one feels a sense of gratitude for another, then one will naturally begin to relate to that person with increased affection-a critical ingredient for compassion.

\section{Affection and its role in Modules IV and V}

In the CBCT integrative model, identification and gratitude are intended to enhance the cultivation of affection for others. In this case, affection is being used to translate the Tibetan word "yid- "ong" which conveys someone who is pleasing to the mind (for a more detailed overview, see Cutler and Newland 2015). Under this definition, affection should not be confused with feelings of romantic love. More appropriately, affection can be understood as an endearing way of relating to others characterized 
by a sense of tenderness. In the CBCT integrative model, affection is the most critical ingredient to allow for compassion to arise. If one does not relate to another with some degree of affection, then one will not be motivated to respond to them compassionately. While participants likely relate to some friends and family with a degree of affection, CBCT practices aim to extend this quality of affection to a broader circle of people through processes of critical thinking and cognitive reframing. This emphasis on cognitive reflection as path to affection contrasts common western notions of affection as state primarily driven by emotions. Both Modules IV and V cultivate insights to allow for this extension of affection as a natural outgrowth of relating to others with increased identification and gratitude.

\section{Module VI skill: empathy}

Empathy is the experience of resonating with or understanding the way another person is thinking or feeling. There is robust evidence that feelings of empathy can lead to either a response of personal distress or empathic concern (Batson et al. 1994; Decety et al. 2009; Eisenberg 2000; Eisenberg et al. 1989). An empathic distress response results when one becomes emotionally distressed in response to the suffering of another; in this case, attention becomes more oriented towards self than towards the person suffering. In contrast, a response of empathic concern remains other-oriented; in this case, one feels a sense of concern for the other and remains focused on their situation. Empathic concern can thus elicit and sustain a motivation to help. More recent advances in affective neuroscience have shown distinct differences in neural circuitry patterns when someone experiences an empathic distress response versus an empathic concern response (Singer and Lamm 2009). In the CBCT integrative model, the affection developed in Modules IV and V is proposed as a means to strengthen the focus on the other when confronted by suffering and to buffer against the likelihood of an empathic distress response. We propose that when one relates to another with increased affection, one will be more focused on their suffering and how it may be alleviated and not be subsumed by one's own stress response. This view is consistent with research by Batson and colleagues who showed valuing the welfare of others as antecedent to empathic concern. In Batson's model, empathic concern relies on perceiving the needs of another, valuing their welfare, and taking their perspective (Batson et al. 2007).

It is important to note that the merits of empathy have been debated among psychologists, most notably Paul Bloom, who argues that whom we feel empathy for is often biased and short-sighted which can lead to immoral decision-making (Bloom 2017). We acknowledge the importance of this critique; it is for this reason that the practice in Module IV: Cultivating Impartiality, wherein participants develop increased identification with others, is of critical importance towards cultivating extended compassion that is less subject to pre-disposed biases. 


\section{Resilience}

In the CBCT integrative model, skills developed in the foundational practice and Modules I-III are expected to enhance individual resilience. Resilience has been studied across a variety of disciplines and contexts including psychology (Fletcher and Sarkar 2013; Rutter 1987), sociology (Hall and Lamont 2013), and ecology (Holling 1973). While definitions vary, in the context of the CBCT integrative model, we primarily refer to resilience to consider psychological traits and processes that enhance a person's ability to recover, adapt, and ultimately grow in response to adverse life experiences. In CBCT training, the security priming cultivated in the foundational practice can be used as a tool to regulate the body when aroused or distressed. Then, the attention cultivated in Module I is intended to foster participants' ability to choose where to place their attention, potentially disengaging from distracting or harmful thoughts. Skills from Module II support participants in observing their own mental activity through the use of meta-awareness. Further, Module II practice is intended to lead to more accurate and granular perception of one's thoughts and feelings as well as an understanding that thoughts do not necessarily align directly with external realities. Module III practice goes a step further by asking participants to actively engage in cognitive re-appraisal strategies to respond to their own challenges with kindness and self-acceptance based on the understanding that adverse events are part of every human life and are due to many causes and factors outside of the individual's full control. Together, the skills cultivated in the foundational practice and Modules I-III are intended to allow participants to respond to challenges with enhanced resilience.

Importantly, the skills identified in the CBCT integrative model to promote resilience are limited to components directly targeted in CBCT training. The model is not intended to reflect an exhaustive list of factors that may promote resilience. For instance, the prior literature suggests resilience is moderated by other psychological factors which the proposed model does not directly address such as self-efficacy (Schaubroeck and Merritt 1997) or positive affect (Tugade and Fredrickson 2004), though these two factors in particular are likely encouraged by CBCT practices in secondary ways. Furthermore, larger systems and structures related to economic status, environment, cultural norms, and laws and policies are known to significantly affect personal and social resilience (Bottrell 2009; Hall and Lamont 2013; Walker et al. 2006). These findings are consistent with social ecological theories which illustrate the ways in which behavior is subject to multiple levels of influence including societal, communal, organizational, social, and personal (Bronfenbrenner 1977; McLeroy et al. 2016). In keeping with this view, we do not espouse that resilience can be understood as simply an intrapersonal trait divorced from factors such as social support, culture, or socioeconomic status. We acknowledge that social and systemic factors are of critical importance to the promotion and support of resilience, but they are outside the scope of intervening factors explicitly addressed in Modules I-III of CBCT training. 


\section{Compassion}

The skills developed in Modules IV-VI are expected to increase extended compassion for others. Identification (developed in Module IV) and gratitude (developed in Module V) are both expected to contribute to a sense of affection for a wider group of people. This sense of affection is paired with a growing awareness of others' vulnerabilities through enhanced empathy (developed in Module VI). As such, the final three modules train participants to both notice the suffering of others and feel motivated to help as a result of increased and more inclusive affection. In this way, skills developed in Modules IV-VI are potentially supportive of forms of social resilience, which is defined as the ability of groups to sustain wellbeing in the face of challenges (Hall and Lamont 2013). Module V explicitly trains participants to consider the ways in which their wellbeing is dependent on other people and systems, often referred to as "interdependence." We expect that a growing awareness of their interdependent nature combined with a motivation to help may foster forms of social resilience by empowering individuals to appreciate the ways their actions can affect the communities in which they live. Thus, while CBCT is an intervention that targets individuals, efforts to expand compassion to growing networks could have social and societal implications.

\section{Wellbeing}

In the CBCT integrative model, wellbeing is conceived of as a state of positive psychosocial health that is supported by intrapersonal skills fostering resilience and interpersonal skills enhancing compassion for others. We propose that both pathways promote wellbeing and are mutually supportive. As stated previously, participation in CBCT has been associated with reductions in stress and depression (Desbordes et al. 2012; Mascaro et al. 2016). One possible explanation for this finding is that if a person feels better equipped to respond to personal challenges, then he or she should have more available energy to consider the needs of others. Similarly, we expect relating to others with compassion would promote feelings of social connection which support resilience. This conceptualization of wellbeing shares some similarities with other wellbeing models. For instance, Ryff's psychological wellbeing framework includes constructs such as self-acceptance and positive social relationships (Ryff 1989, 2014). There are strong correlations between self-compassion and psychological wellbeing (Zessin et al. 2015), though less is known about the relationship between compassion for others and wellbeing. Lopez et al. did not find a significant association between compassion for others and wellbeing (2018), however, compassion training has been previously shown to boost positive affect (Klimecki et al. 2013) and self-reported happiness (Mongrain et al. 2011). Further research is necessary to better delineate the relationship between resilience, compassion for others, and wellbeing. 


\section{Discussion}

This article proposes a model for understanding CBCT's key components and mechanisms. While recent research on CBCT has suggested a number of benefits from its practice, little research has addressed how and why these practices are effective. The CBCT integrative model proposes a framework for how key skills developed in each module may lead to three principal outcomes of interest: resilience, compassion, and wellbeing. The NIH Science of Behavior Change Program identified three target classes that are central to behavior change: self-regulation, stress resilience and stress reactivity, and interpersonal and social processes (Nielsen et al. 2018). The proposed CBCT mechanisms of change include skills relevant to each identified class. Module I through Module III primarily involve developing intrapersonal skills intended to foster self-regulation and individual-level resilience. Module IV through Module VI aims to develop other oriented, interpersonal skills that are necessary for extended compassion. The CBCT integrative model proposes that wellbeing is contingent on both personal resiliency and compassion for others. We expect these two factors are mutually reinforcing-i.e. greater resilience may prevent burnout and thereby facilitate the availability of more energy to care for others; likewise, experiencing greater compassion for others may allow for enhanced resiliency as individuals can respond to their own difficulties from a broader context.

While the CBCT integrative model provides a conceptual model indicating the proposed relationship between key skills and outcomes developed in CBCT training, we expect a host of other factors not addressed in the model to likely moderate effects of CBCT. For example, this model does not consider individual features and contexts relevant to the participant including demographic variables, health and psychological functioning, or prior exposure to contemplative practices. To date, there is limited research directly investigating moderating variables pertinent to compassion training. One study led by Goldin and Jazaieri found that demographic variables did not moderate effectiveness of compassion training, though they did find that psychological functioning including perceived stress, mindfulness skills, and cognitive reappraisal self-efficacy did moderate reductions in fear of self-compassion after compassion training (2017). In a different study among a sample of medical students participating in a CBCT intervention, Mascaro et al. found that those with higher depression scores at baseline showed the largest increase in compassion for others after CBCT was complete (2016), suggesting those in mental distress may particularly benefit from CBCT training.

Similarly, the CBCT integrative model does not account for cultural and environmental factors that may affect participants' engagement with and benefit from CBCT. Health behavior interventions at large have been criticized for their emphasis on targeting individual level factors without consideration for the larger systems and social structures that shape behavior (Holman and Borgstrom 2016; Stokols 1996; Thorlindsson 2011). There is increasing research utilizing social network theory to understand the ways in which social ties and position within a social network influence a myriad of behaviors (Borgatti et al. 2009). For instance, risk for obesity increases by $57 \%$ if a friend becomes obese (Christakis and Fowler 2007), suggesting a contagion factor for 
unhealthful attitudes and behaviors. It is possible that healthful behaviors may also be transmitted through social networks. We do not yet have sufficient data to understand the ways in which dynamic social and cultural processes influence engagement with CBCT as well compassionate behavior, but we advise that future research should consider the impact of social networks and cultural contexts. Given that CBCT's principal goal is to enhance compassion for others, it is essential that future research consider social and systemic factors that may influence potential outcomes. It is our intention that the CBCT integrative model will provide a theoretical basis to study how different populations experience and potentially benefit from CBCT training.

\section{Conclusion}

The CBCT integrative model provides a framework for future theory-driven research on CBCT. Previous research on CBCT has primarily examined changes in health outcomes after participation in CBCT training. It is our goal that the CBCT integrative model provides a conceptual framework to understand the psychosocial processes that influence such change. The proposed mechanistic relationships in the CBCT integrative model are drawn primarily from the Indo-Tibetan Buddhist lojong framework from which CBCT was adapted. It will be important for future research to align identified constructs with appropriate empirical measures to test the effectiveness of the model. The constructs outlined in the model are not exhaustive; we expect other factors to also impact the outcomes of compassion training. Next steps for future research include addressing the following questions: (1) Can the proposed mechanisms in a CBCT intervention be confirmed? (2) What is the relationship between identified intrapersonal skills (e.g. resilience) and interpersonal skills (e.g. compassion)? The CBCT integrative model assumes intrapersonal and interpersonal skills are mutually reinforcing, but this assumption should be addressed empirically. (3) What are the impacts of dosage and sequence for a CBCT intervention? A 10-week CBCT intervention is divided roughly into thirds with equal emphasis given to present-moment practices (Modules I and II), self-compassion practices (Module III), and other-oriented compassion practices (Modules IV-VI). It will be important for future research to examine the impact of sequence and dosage on potential beneficial outcomes. (4) How should the current CBCT integrative model be revised according to empirical findings? An improved understanding of the mechanisms present in a CBCT intervention could lend important insight regarding how to optimize and personalize the intervention to meet the needs of diverse populations.

Acknowledgements We thank Bobbi Patterson for her input on an earlier draft of this paper.

\section{Compliance with ethical standards}

Conflict of interest Authors Marcia Ash, Timothy Harrison, and Lobsang Tenzin Negi are employed by the Center for Contemplative-Science and Compassion-Based Ethics at Emory University. Authors Melissa Pinto and Ralph DiClemente are on the Advisory Board of the Center for Contemplative Science and Compassion-Based Ethics at Emory University. Lobsang Tenzin Negi is the developer of $\mathrm{CBCT}^{\circledR}$, but neither he nor any of the other authors hold a financial stake in the intellectual property rights of $\mathrm{CBCT}^{\circledR}$. 
Open Access This article is licensed under a Creative Commons Attribution 4.0 International License, which permits use, sharing, adaptation, distribution and reproduction in any medium or format, as long as you give appropriate credit to the original author(s) and the source, provide a link to the Creative Commons licence, and indicate if changes were made. The images or other third party material in this article are included in the article's Creative Commons licence, unless indicated otherwise in a credit line to the material. If material is not included in the article's Creative Commons licence and your intended use is not permitted by statutory regulation or exceeds the permitted use, you will need to obtain permission directly from the copyright holder. To view a copy of this licence, visit http://creativecommons.org/licen ses/by/4.0/.

\section{References}

Asanga, Rahula W., and S.B. Webb. 2001. Abhidharmasamuccaya. Fremont: Asian Humanities Press.

Ashar, Y.K., J.R. Andrews-Hanna, S. Dimidjian, and T.D. Wager. 2016. Towards a neuroscience of compassion: A brain systems-based model and research agenda. In Positive neuroscience, ed. J.D. Greene, I. Morrison, and M.E.P. Seligman, 1-27. New York: Oxford University Press.

Bartlett, M.Y., P. Condon, J. Cruz, J. Baumann, and D. Desteno. 2012. Gratitude: Prompting behaviours that build relationships. Cognition and Emotion 26 (1): 2-13. https://doi.org/10.1080/02699 931.2011.561297.

Bartlett, M.Y., and D. DeSteno. 2006. Gratitude and prosocial behavior: Helping when it costs you. Psychological Science 17 (4): 319-325. https://doi.org/10.1111/j.1467-9280.2006.01705.x.

Batson, C.D., J.H. Eklund, V.L. Chermok, J.L. Hoyt, and B.G. Ortiz. 2007. An additional antecedent of empathic concern: Valuing the welfare of the person in need. Journal of Personality and Social Psychology 93 (1): 65-74. https://doi.org/10.1037/0022-3514.93.1.65.

Batson, C.D., J. Fultz, and P.A. Schoenrade. 1994. Distress and empathy: Two qualitatively distinct vicarious emotions with different motivational consequences. In Reaching out: Caring, altruism, and prosocial behavior, ed. B. Puka and B. Puka, 57-75. New York: Garland Publishing.

Bloom, P. 2017. Against empathy: The case for rational compassion. New York: Random House.

Borgatti, S.P., A. Mehra, D.J. Brass, and G. Labianca. 2009. Network analysis in the social sciences. Science 323 (5916): 892-895. https://doi.org/10.1126/science.1165821.

Bottrell, D. 2009. Understanding 'marginal'perspectives: Towards a social theory of resilience. Qualitative Social Work 8 (3): 321-339.

Bowlby, J. 1982. Attachment and loss: Attachment, vol. 1, 2nd ed. New York: Basic Books.

Bowlby, J. 1988. A secure base: Clinical applications of attachment theory. London: Routledge.

Bronfenbrenner, U. 1977. Toward an experimental ecology of human development. American Psychologist 32 (7): 513.

Christakis, N.A., and J.H. Fowler. 2007. The spread of obesity in a large social network over 32 years. New England Journal of Medicine 357 (4): 370-379. https://doi.org/10.1056/NEJMsa066082.

Collins, N.L., and S.J. Read. 1994. Cognitive representations of attachment: The structure and function of working models. In Attachment processes in adulthood, ed. K. Bartholomew and D. Perlman, 53-90. London, England: Jessica Kingsley Publishers.

Condon, P., G. Desbordes, W.B. Miller, and D. DeSteno. 2013. Meditation increases compassionate responses to suffering. Psychological Science 24 (10): 2125-2127. https://doi.org/10.1177/09567 97613485603.

Cutler, J., and G. Newland. 2015. The great treatise on the stages of the path to enlightenment, vol. 1. Ithaca, NY: Snow Lion Publications.

Dahl, C.J., A. Lutz, and R.J. Davidson. 2016. Cognitive processes are central in compassion meditation. Trends in Cognitive Sciences 20 (3): 161-162. https://doi.org/10.1016/j.tics.2015.12.005.

Dalai Lama [Tenzin Gyatso] (2005). Essence of the Heart Sutra: The Dalai Lama's Heart of Wisdom Teachings (Trans. Ed.) Geshe Thupten Jinpa. Boston: Wisdom Publications.

Decety, J., K.D. Craig, W. Ickes, C.D. Batson, K.S. Blair, R.J.R. Blair, et al. 2009. The social neuroscience of empathy. Cambridge, MA: MIT Press.

Desbordes, G., L.T. Negi, T.W. Pace, B.A. Wallace, C.L. Raison, and E.L. Schwartz. 2012. Effects of mindful-attention and compassion meditation training on amygdala response to emotional 
stimuli in an ordinary, non-meditative state. Frontiers in Human Neuroscience 6: 292. https://doi. org/10.3389/fnhum.2012.00292.

Dodds, S.E., T.W. Pace, M.L. Bell, M. Fiero, L.T. Negi, C.L. Raison, and K.L. Weihs. 2015. Feasibility of cognitively-based compassion training (CBCT) for breast cancer survivors: A randomized, wait list controlled pilot study. Supportive Care in Cancer 23 (12): 3609-3611. https://doi.org/10.1007/ s00520-015-2926-z.

Eisenberg, N. 2000. Emotion, regulation, and moral development. Annual Review of Psychology 51: 665697. https://doi.org/10.1146/annurev.psych.51.1.665.

Eisenberg, N., R.A. Fabes, P.A. Miller, J. Fultz, R. Shell, R.M. Mathy, and R.R. Reno. 1989. Relation of sympathy and personal distress to prosocial behavior: A multimethod study. Journal of Personality and Social Psychology 57 (1): 55-66. https://doi.org/10.1037/0022-3514.57.1.55.

Emmons, R.A., and M.E. McCullough. 2003. Counting blessings versus burdens: An experimental investigation of gratitude and subjective well-being in daily life. Journal of Personality and Social Psychology 84 (2): 377-389. https://doi.org/10.1037/0022-3514.84.2.377.

Fletcher, D., and M. Sarkar. 2013. Psychological resilience: A review and critique of definitions, concepts, and theory. European Psychologist 18 (1): 12.

Fredrickson, B.L., M.A. Cohn, K.A. Coffey, J. Pek, and S.M. Finkel. 2008. Open hearts build lives: Positive emotions, induced through loving-kindness meditation, build consequential personal resources. Journal of Personality and Social Psychology 95 (5): 1045-1062. https://doi.org/10.1037/a0013 262.

Frias, A., P.C. Watkins, A.C. Webber, and J.J. Froh. 2011. Death and gratitude: Death reflection enhances gratitude. The Journal of Positive Psychology 6 (2): 154-162. https://doi.org/10.1080/17439 760.2011.558848.

Gilbert, P. 2014. The origins and nature of compassion focused therapy. British Journal of Clinical Psychology 53 (1): 6-41. https://doi.org/10.1111/bjc.12043.

Goetz, J.L., D. Keltner, and E. Simon-Thomas. 2010. Compassion: An evolutionary analysis and empirical review. Psychological Bulletin 136 (3): 351-374. https://doi.org/10.1037/a0018807.

Goldin, P.R., and H. Jazaieri. 2017. Investigating moderators of compassion meditation training in a community sample. Mindfulness. https://doi.org/10.1007/s12671-017-0857-0.

Gonzalez-Hernandez, E., R. Romero, D. Campos, D. Burichka, R. Diego-Pedro, R. Baños, et al. 2018. Cognitively-based compassion training (CBCT) in breast cancer survivors: A randomized clinical trial study. Integrative Cancer Therapies. https://doi.org/10.1177/1534735418772095.

Hall, P.A., and M. Lamont. 2013. Social resilience in the neoliberal era. Cambridge: Cambridge University Press.

Hamlin, J.K., N. Mahajan, Z. Liberman, and K. Wynn. 2013. Not like me=Bad: infants prefer those who harm dissimilar others. Psychological Science 24 (4): 589-594. https://doi.org/10.1177/09567 97612457785.

Hofmann, S.G., P. Grossman, and D.E. Hinton. 2011. Loving-kindness and compassion meditation: Potential for psychological interventions. Clinical Psychology Review 31 (7): 1126-1132. https:// doi.org/10.1016/j.cpr.2011.07.003.

Holling, C.S. 1973. Resilience and stability of ecological systems. Annual Review of Ecology and Systematics 4 (1): 1-23.

Holman, D., and E. Borgstrom. 2016. Applying social theory to understand health-related behaviours. Medical Humanities 42 (2): 143-145.

Jazaieri, H., G.T. Jinpa, K. McGonigal, E.L. Rosenberg, J. Finkelstein, E. Simon-Thomas, et al. 2012. Enhancing compassion: A randomized controlled trial of a compassion cultivation training program. Journal of Happiness Studies 14 (4): 1113-1126. https://doi.org/10.1007/s1090 2-012-9373-z.

Jazaieri, H., K. McGonigal, T. Jinpa, J.R. Doty, J.J. Gross, and P.R. Goldin. 2013. A randomized controlled trial of compassion cultivation training: Effects on mindfulness, affect, and emotion regulation. Motivation and Emotion 38 (1): 23-35. https://doi.org/10.1007/s11031-013-9368-z.

Jazaieri, H., K. McGonigal, I.A. Lee, T. Jinpa, J.R. Doty, J.J. Gross, and P.R. Goldin. 2017. Altering the trajectory of affect and affect regulation: the impact of compassion training. Mindfulness. https:// doi.org/10.1007/s12671-017-0773-3.

Jha, A.P., J. Krompinger, and M.J. Baime. 2007. Mindfulness training modifies subsystems of attention. Cognitive, Affective, \& Behavioral Neuroscience 7 (2): 109-119. https://doi.org/10.3758/ CABN.7.2.109. 
Jinpa, T., S. Gyalchok, and K. Gyaltsen. 2014. Mind training: The great collection, vol. 1. New York: Simon and Schuster.

Kabat-Zinn, J. 2013. Full catastrophe living: Using the wisdom of your body to face stress, pain, and illness. New York, NY: Bantam Books.

Kirby, J.N. 2017. Compassion interventions: The programmes, the evidence, and implications for research and practice. Psychology and Psychotherapy 90 (3): 432-455. https://doi.org/10.1111/papt.12104.

Klimecki, O.M., S. Leiberg, C. Lamm, and T. Singer. 2013. Functional neural plasticity and associated changes in positive affect after compassion training. Cerebral Cortex 23 (7): 1552-1561. https:// doi.org/10.1093/cercor/bhs142.

Kyabgon, T. 2007. The practice of Lojong: Cultivating compassion through training the mind. Boulder: Shambhala Publications.

Lama, D. 2005. Essence of the heart sutra: The Dalai Lama's heart of wisdom teachings (Trans. Ed.) Geshe Thupten Jinpa. Boston: Wisdom Publications.

Lazarus, R.S. 1991. Emotion and adaptation. New York: Oxford University Press.

Leiberg, S., O. Klimecki, and T. Singer. 2011. Short-term compassion training increases prosocial behavior in a newly developed prosocial game. PLOS ONE 6 (3): e17798. https://doi.org/10.1371/journ al.pone.0017798.

Levine, M., A. Prosser, D. Evans, and S. Reicher. 2005. Identity and emergency intervention: How social group membership and inclusiveness of group boundaries shape helping behavior. Personality and Social Psychology Bulletin 31 (4): 443-453. https://doi.org/10.1177/0146167204271651.

LoParo, D., S.A. Mack, B. Patterson, L.T. Negi, and N.J. Kaslow. 2018. The efficacy of cognitivelybased compassion training for African American suicide attempters. Mindfulness. https://doi. org/10.1007/s12671-018-0940-1.

Lopez, A., R. Sanderman, A.V. Ranchor, and M.J. Schroevers. 2018. Compassion for others and selfcompassion: levels, correlates, and relationship with psychological well-being. Mindfulness 9 (1): 325-331. https://doi.org/10.1007/s12671-017-0777-z.

Lutz, A., J. Brefczynski-Lewis, T. Johnstone, and R.J. Davidson. 2008a. Regulation of the neural circuitry of emotion by compassion meditation: Effects of meditative expertise. PLOS ONE 3 (3): e1897. https://doi.org/10.1371/journal.pone.0001897.

Lutz, A., A.P. Jha, J.D. Dunne, and C.D. Saron. 2015. Investigating the phenomenological matrix of mindfulness-related practices from a neurocognitive perspective. American Psychologist 70 (7): 632-658. https://doi.org/10.1037/a0039585.

Lutz, A., H.A. Slagter, J.D. Dunne, and R.J. Davidson. 2008b. Attention regulation and monitoring in meditation. Trends in Cognitive Sciences 12 (4): 163-169. https://doi.org/10.1016/j. tics.2008.01.005.

MacBeth, A., and A. Gumley. 2012. Exploring compassion: A meta-analysis of the association between self-compassion and psychopathology. Clinical Psychology Review 32 (6): 545-552. https://doi. org/10.1016/j.cpr.2012.06.003.

Mascaro, J., A. Darcher, L.T. Negi, and C. Raison. 2015. The neural mediators of kindness-based meditation: A theoretical model. Frontiers in Psychology 6: 109. https://doi.org/10.3389/fpsyg .2015.00109.

Mascaro, J., S. Kelley, A. Darcher, L.T. Negi, C. Worthman, A. Miller, and C. Raison. 2016. Meditation buffers medical student compassion from the deleterious effects of depression. The Journal of Positive Psychology. https://doi.org/10.1080/17439760.2016.1233348.

Mascaro, J., J. Rilling, L.T. Negi, and C. Raison. 2013. Compassion meditation enhances empathic accuracy and related neural activity. Social Cognitive and Affective Neuroscience 8 (1): 48-55. https:// doi.org/10.1093/scan/nss095.

McLeroy, K.R., D. Bibeau, A. Steckler, and K. Glanz. 2016. An ecological perspective on health promotion programs. Health Education Quarterly 15 (4): 351-377. https://doi.org/10.1177/1090198188 01500401.

Mikulincer, M. 1997. Adult attachment style and information processing: Individual differences in curiosity and cognitive closure. Journal of Personality and Social Psychology 72 (5): 1217-1230. https ://doi.org/10.1037/0022-3514.72.5.1217.

Mikulincer, M., P.R. Shaver, O. Gillath, and R.A. Nitzberg. 2005. Attachment, caregiving, and altruism: Boosting attachment security increases compassion and helping. Journal of Personality and Social Psychology 89 (5): 817-839. https://doi.org/10.1037/0022-3514.89.5.817.

Mikulincer, M., P.R. Shaver, N. Bar-On, and B.K. Sahdra. 2014. Security enhancement, self-esteem threat, and mental depletion affect provision of a safe haven and secure base to a romantic partner. 
Journal of Social and Personal Relationships 31 (5): 630-650. https://doi.org/10.1177/02654 07514525887.

Mongrain, M., J.M. Chin, and L.B. Shapira. 2011. Practicing compassion increases happiness and selfesteem. Journal of Happiness Studies 12 (6): 963-981. https://doi.org/10.1007/s10902-010-9239-1.

Neff, K. 2003. Self-compassion: An alternative conceptualization of a healthy attitude toward oneself. Self and Identity 2 (2): 85-101. https://doi.org/10.1080/15298860309032.

Neff, K. 2015. The self-compassion scale is a valid and theoretically coherent measure of self-compassion. Mindfulness 7 (1): 264-274. https://doi.org/10.1007/s12671-015-0479-3.

Neff, K., and C.K. Germer. 2013. A pilot study and randomized controlled trial of the mindful self-compassion program. Journal of Clinical Psychology 69 (1): 28-44. https://doi.org/10.1002/jclp.21923

Neff, K., and E. Pommier. 2013. The relationship between self-compassion and other-focused concern among college undergraduates, community adults, and practicing meditators. Self and Identity 12 (2): 160-176. https://doi.org/10.1080/15298868.2011.649546.

Negi, L.T. 2005. Cognitively-based compassion training protocol.

Nielsen, L., M. Riddle, J.W. King, W.M. Aklin, W. Chen, et al. 2018. The NIH science of behavior change program: Transforming the science through a focus on mechanisms of change. Behaviour Research and Therapy 101: 3-11. https://doi.org/10.1016/j.brat.2017.07.002.

Ozawa-de Silva, B.R., and B. Dodson-Lavelle. 2011. An education of heart and mind: Issues in teaching cognitiely-based compassion training to children. Practical Matters 4: 1-28.

Pace, T.W., L. Negi, B. Donaldson-Lavelle, B. Ozawa-de Silva, S. Reddy, S. Cole, et al. 2012. P02.119. Cognitively-based compassion training reduces peripheral inflammation in adolescents in foster care with high rates of early life adversity. BMC Complementary and Alternative Medicine. https:// doi.org/10.1186/1472-6882-12-s1-p175.

Pace, T.W., L.T. Negi, D.D. Adame, S.P. Cole, T.I. Sivilli, T.D. Brown, et al. 2009. Effect of compassion meditation on neuroendocrine, innate immune and behavioral responses to psychosocial stress. Psychoneuroendocrinology 34 (1): 87-98. https://doi.org/10.1016/j.psyneuen.2008.08.011.

Pace, T.W., L.T. Negi, B. Dodson-Lavelle, B. Ozawa-de Silva, S.D. Reddy, S.P. Cole, et al. 2013. Engagement with cognitively-based compassion training is associated with reduced salivary C-reactive protein from before to after training in foster care program adolescents. Psychoneuroendocrinology 38 (2): 294-299. https://doi.org/10.1016/j.psyneuen.2012.05.019.

Reddy, S.D., L.T. Negi, B. Dodson-Lavelle, B. Ozawa-de Silva, T.W. Pace, S.P. Cole, et al. 2012. Cognitive-based compassion training: A promising prevention strategy for at-risk adolescents. Journal of Child and Family Studies 22 (2): 219-230. https://doi.org/10.1007/s10826-012-9571-7.

Rutter, M. 1987. Psychosocial resilience and protective mechanisms. American Journal of Orthopsychiatry 57 (3): 316-331.

Ryff, C. 1989. Happiness is everything, or is it? Explorations on the meaning of psychological well-being. Journal of Personality and Social Psychology 57 (6): 1069-1081. https://doi. org/10.1037/0022-3514.57.6.1069.

Ryff, C. 2014. Psychological well-being revisited: Advances in the science and practice of eudaimonia. Psychotherapy and Psychosomatics 83 (1): 10-28. https://doi.org/10.1159/000353263.

Schaubroeck, J., and D.E. Merritt. 1997. Divergent effects of job control on coping with work stressors: The key role of self-efficacy. Academy of Management Journal 40 (3): 738-754.

Schooler, J.W. 2002. Re-representing consciousness: Dissociations between experience and metaconsciousness. Trends in Cognitive Sciences 6 (8): 339-344. https://doi.org/10.1016/S1364 -6613(02)01949-6.

Schooler, J.W., J. Smallwood, K. Christoff, T.C. Handy, E.D. Reichle, and M.A. Sayette. 2011. Metaawareness, perceptual decoupling and the wandering mind. Trends in Cognitive Sciences 15 (7): 319-326. https://doi.org/10.1016/j.tics.2011.05.006.

Schuling, R., M. Huijbers, H. Jansen, R. Metzemaekers, E.V. Den Brink, F. Koster, et al. 2018. The cocreation and feasibility of a compassion training as a follow-up to mindfulness-based cognitive therapy in patients with recurrent depression. Mindfulness 9 (2): 412-422. https://doi.org/10.1007/ s12671-017-0783-1.

Seppala, E.M.S.-T., S. Brown, M. Worline, D.C. Cameron, and J.R. Doty (eds.). 2017. The Oxford handbook of compassion science. New York: Oxford University Press.

Sheldon, K.M., and S. Lyubomirsky. 2006. How to increase and sustain positive emotion: The effects of expressing gratitude and visualizing best possible selves. The Journal of Positive Psychology 1 (2): 73-82. https://doi.org/10.1080/17439760500510676. 
Shonin, E., W. Van Gordon, A. Compare, M. Zangeneh, and M.D. Griffiths. 2014. Buddhist-derived loving-kindness and compassion meditation for the treatment of psychopathology: A systematic review. Mindfulness 6 (5): 1161-1180. https://doi.org/10.1007/s12671-014-0368-1.

Singer, T., and C. Lamm. 2009. The social neuroscience of empathy. Annals of the New York Academy of Sciences 1156 (1): 81-96. https://doi.org/10.1111/j.1749-6632.2009.04418.x.

Smallwood, J., and J.W. Schooler. 2015. The science of mind wandering: Empirically navigating the stream of consciousness. Annual Review of Psychology 66 (1): 487-518. https://doi.org/10.1146/ annurev-psych-010814-015331.

Stokols, D. 1996. Translating social ecological theory into guidelines for community health promotion. American Journal of Health Promotion 10 (4): 282-298.

Strauss, C., B. Lever Taylor, J. Gu, W. Kuyken, R. Baer, F. Jones, and K. Cavanagh. 2016. What is compassion and how can we measure it? A review of definitions and measures. Clinical Psychology Review 47: 15-27. https://doi.org/10.1016/j.cpr.2016.05.004.

Thorlindsson, T. 2011. Bring in the social context: Towards an integrated approach to health promotion and prevention. Scandinavian Journal of Public Health 39 (6_suppl): 19-25.

Tsai, M.H., and W.L. Chou. 2016. Attentional orienting and executive control are affected by different types of meditation practice. Consciousness and Cognition 46: 110-126. https://doi.org/10.1016/j. concog.2016.09.020.

Tsang, J.-A., and S.R. Martin. 2019. Four experiments on the relational dynamics and prosocial consequences of gratitude. The Journal of Positive Psychology 14 (2): 188-205. https://doi. org/10.1080/17439760.2017.1388435.

Tugade, M.M., and B.L. Fredrickson. 2004. Resilient individuals use positive emotions to bounce back from negative emotional experiences. Journal of Personality and Social Psychology 86 (2): 320.

van den Hurk, P.A.M., F. Giommi, S.C. Gielen, A.E.M. Speckens, and H.P. Barendregt. 2010. Greater efficiency in attentional processing related to mindfulness meditation. Quarterly Journal of Experimental Psychology 63 (6): 1168-1180. https://doi.org/10.1080/17470210903249365.

Walker, B., J. Anderies, A. Kinzig, and P. Ryan. 2006. Exploring resilience in social-ecological systems through comparative studies and theory development: Introduction to the special issue. Ecology and Society 11 (1): 13.

Weng, H.Y., A.S. Fox, A.J. Shackman, D.E. Stodola, J.Z. Caldwell, M.C. Olson, et al. 2013. Compassion training alters altruism and neural responses to suffering. Psychological Science 24 (7): 11711180. https://doi.org/10.1177/0956797612469537.

Williams, J.M.G. 2010. Mindfulness and psychological process. Emotion 10 (1): 1-7. https://doi. org/10.1037/a0018360.

Winkielman, P., and J.W. Schooler. 2011. Splitting consciousness: Unconscious, conscious, and metaconscious processes in social cognition. European Review of Social Psychology 22 (1): 1-35. https:// doi.org/10.1080/10463283.2011.576580.

Wood, A.M., J.J. Froh, and A.W. Geraghty. 2010. Gratitude and well-being: A review and theoretical integration. Clinical Psychology Review 30 (7): 890-905. https://doi.org/10.1016/j.cpr.2010.03.005.

Wood, A.M., S. Joseph, J. Lloyd, and S. Atkins. 2009. Gratitude influences sleep through the mechanism of pre-sleep cognitions. Journal of Psychosomatic Research 66 (1): 43-48. https://doi. org/10.1016/j.jpsychores.2008.09.002.

Wynn, K., P. Bloom, A. Jordan, J. Marshall, and M. Sheskin. 2017. Not noble savages after all: Limits to early altruism. Current Directions in Psychological Science 27 (1): 3-8. https://doi. org/10.1177/0963721417734875.

Zessin, U., O. Dickhauser, and S. Garbade. 2015. The relationship between self-compassion and wellbeing: A meta-analysis. Applied Psychology: Health and Well-Being 7 (3): 340-364. https://doi. org/10.1111/aphw.12051.

Zhang, H., N.N. Watson-Singleton, S.E. Pollard, D.M. Pittman, D.A. Lamis, N.L. Fischer, et al. 2017. Self-criticism and depressive symptoms: Mediating role of self-compassion. Omega. https://doi. org/10.1177/0030222817729609.

Publisher's Note Springer Nature remains neutral with regard to jurisdictional claims in published maps and institutional affiliations. 
Marcia Ash MPH is a doctoral student in the Department of Behavioral Sciences and Health Education at the Rollins School of Public Health at Emory University. Ash is also a certified Cognitively-Based Compassion Training $\left(\mathrm{CBCT}^{\circledR}\right)$ instructor. Ash holds a Bachelor of Arts in Philosophy, Neuroscience and Psychology from Washington University in St. Louis and a Masters in Public Health (MPH) from the Behavioral Sciences and Health Education Department at the Rollins School of Public Health at Emory University.

Timothy Harrison M.Arch. is the Associate Director for $\mathrm{CBCT}^{\circledR}$ (Cognitively-Based Compassion Training) at the Center for Contemplative Science and Compassion-Based Ethics at Emory University. He oversees CBCT programs, including multiple research initiatives and the teacher certification process. He regularly teaches CBCT nationally and internationally in academic institutions and healthcare settings, and he advises on the tailoring of CBCT for research with unique populations. He holds a master's degree from Harvard University.

Melissa Pinto Ph.D., RN, FSAHM, FAAN is an Associate Professor in the Sue \& Bill Gross School of Nursing at the University of California, Irvine. She has expertise in the area of adolescent and young adult behavioral health, self-management, development and assessment of eHealth and technology-based behavioral health interventions, and psychosocial barriers to mental health treatment for adolescents. She completed her PhD in Nursing Science at the University of Louisville and a KL2 Award at Case Western Reserve University. Dr. Pinto is a Fellow of the Society for Adolescent Health and Medicine and the American Academy of Nursing.

Ralph DiClemente Ph.D. is Chair of the Department of Social and Behavioral Sciences and Associate Dean of Public Health Innovation at New York University. Dr. DiClemente has focused on developing intervention packages that blend community and technology-based approaches that are designed to optimize program effectiveness and enhance programmatic sustainability. He has published extensively in the area of adolescent health, particularly HIV/STD prevention, among adolescents and young adults, and in adolescent vaccine programs for influenza and HPV prevention. Dr. DiClemente holds a PhD in Health Psychology from the University of California, San Francisco after completing a SCM at the Harvard School of Public Health.

Lobsang Tenzin Negi Ph.D. is a Professor of Pedagogy in the Department of Religion at Emory University. He is also the Executive Director of the Center for Contemplative Science and Compassion-Based Ethics as well as the developer of $\mathrm{CBCT}^{\circledR}$ (Cognitively-Based Compassion Training). He is a former monk who completed his monastic education at Drepung Loseling Monastery in South India where he received the Geshe Lharampa Degree - the highest academic degree granted in the Tibetan Buddhist tradition. He completed his PhD at Emory University where he studied traditional Buddhist and contemporary western approaches to emotions and their impact on wellness.

\section{Affiliations}

\section{Marcia Ash ${ }^{1} \cdot$ Timothy Harrison ${ }^{2} \cdot$ Melissa Pinto $^{3} \cdot$ Ralph DiClemente ${ }^{4}$. Lobsang Tenzin Negi ${ }^{2}$}

Timothy Harrison

timothy.harrison@emory.edu

Melissa Pinto

mdpinto@uci.edu

Ralph DiClemente

rdj438@nyu.edu

Lobsang Tenzin Negi

snegi@emory.edu 
1 Rollins School of Public Health, Emory University, 1531 Clifton Rd. NE, Room 549, Atlanta, GA 30322, USA

2 Center for Contemplative Science and Compassion-Based Ethics, Emory University, 1599 Clifton Rd. NE, Atlanta, GA 30322, USA

3 Sue \& Bill Gross School of Nursing, University of California, Irvine, 284 Berk Hall, Room 100D, Irvine, CA 92967, USA

4 Department of Social and Behavioral Sciences, College of Global Public Health, New York University, New York, NY, USA 